\title{
Reliability of self-reported sun exposure in Canadian women and estimation of lifetime exposure to vitamin D from sun and diet
}

\author{
Linda S Cook ${ }^{1,2,3, *}$, Bevin L Moon ${ }^{1}$, Yan Dong ${ }^{1}$ and Heather K Neilson ${ }^{2}$ \\ 'Division of Epidemiology and Biostatistics, Department of Internal Medicine, MSC10 5550, 1 University of \\ New Mexico, Albuquerque, NM 87131-0001, USA: ${ }^{2}$ Alberta Health Services, Calgary, Alberta, Canada: \\ ${ }^{3}$ Department of Community Health Sciences, University of Calgary, Calgary, Alberta, Canada
}

Submitted 4 November 2012: Final revision received 25 March 2013: Accepted 4 June 2013: First published online 25 July 2013

\begin{abstract}
Objective: To assess the inter-method reliability of the Ovarian Cancer in Alberta (OVAL) survey developed to estimate adult vitamin D exposure from sun and diet for every tenth year, against the longer Geraldton Skin Cancer Prevention Survey (the assumed 'gold standard'). We also estimated total vitamin D exposure using the OVAL survey.

Design: A randomized crossover design to assess the inter-method reliability of sun exposure (OVAL $v$. Geraldton survey), using intra-class correlation and estimated total vitamin D exposure from sun and diet.

Setting: Calgary, Alberta, Canada.

Subjects: Randomly selected women ( $n$ 90) aged 40-79 years.

Results: The average lifetime sun exposure of $13913 \mathrm{~h}$ (average $411 \mathrm{~h} /$ year) from the Geraldton survey was not significantly different from the $13034 \mathrm{~h}$ (average $385 \mathrm{~h}$ /year) from the OVAL survey for periods with sufficient UV radiation to stimulate vitamin D production. The intra-class correlation coefficient for average lifetime sun exposure was $0 \cdot 77(95 \%$ CI $0 \cdot 69,0 \cdot 86)$; the annual average was $0 \cdot 60$ (95\% CI 0.47, 0.74). Estimated vitamin D from diet and supplements increased with age.

Conclusions: Our OVAL survey reliably estimated adult sun exposure relative to the Geraldton survey, suggesting that assessing sun exposure every tenth year is a reliable and efficient method for estimating sun contributions to lifetime vitamin D exposure.
\end{abstract}

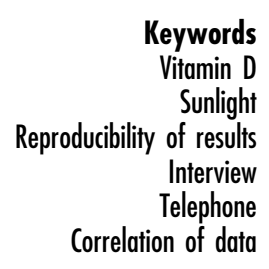

A flurry of epidemiological research into possible preventive roles for vitamin $\mathrm{D}$ in chronic diseases such as $\mathrm{CVD}^{(1,2)}$, autoimmune disease ${ }^{(3)}$ and cancer ${ }^{(4)}$ has been conducted over the past decade. The quality of evidence from these studies has relied heavily upon the means of vitamin $\mathrm{D}$ exposure measurement ${ }^{(5)}$. Humans obtain vitamin D via exposure to UVB radiation in sunlight as well as from food and supplements ${ }^{(4)}$.

Self-reporting is a feasible method for assessing lifetime vitamin D exposure in large epidemiological studies, but has known limitations ${ }^{(6)}$. One of the earliest and most detailed self-report methods for assessing lifetime sun exposure is the Geraldton Skin Cancer Prevention Survey ${ }^{(7,8)}$, hereafter referred to as the 'Geraldton survey'. The survey involves self-completion of a pre-interview residential and occupational history calendar covering each year from age 8 years to the respondent's present age, followed by a face-to-face interview. This survey has acceptable test-retest reliability ${ }^{(7)}$, criterion validity ${ }^{(9)}$ and reliability with comparable measures ${ }^{(7,10)}$, and was associated with cutaneous indicators of sun damage in one study $^{(7)}$. However, it imposes appreciable respondent burden and findings for females, who may have poorer recall than males ${ }^{(10)}$, have been reported only in two studies $^{(10,11)}$. Furthermore, the Geraldton survey does not address dietary sources of vitamin D. Questionnaires have been designed specifically to measure dietary vitamin D exposure (e.g. references 12-15) but these questionnaires focus upon relatively recent consumption, within the past year.

We developed an efficient, adult lifetime, telephoneadministered questionnaire specifically for estimating total vitamin D exposure in Canadian women based on sun and dietary assessment for every tenth year of adult life (e.g. age $20,30,40$ years, etc.). The aim of the present study was to appraise the utility of our questionnaire for use in a larger study known as the Ovarian Cancer in Alberta (OVAL) Study. Our primary objective was to assess the inter-method 
reliability of our abbreviated sun exposure questionnaire (the OVAL survey) against the longer Geraldton survey (the assumed 'gold standard') and our secondary objective was to estimate total vitamin D exposure, from sun and dietary sources, using the OVAL survey.

\section{Experimental methods}

\section{Recruitment}

The study was conducted according to the guidelines laid down in the Declaration of Helsinki and all procedures involving human subjects/patients were approved by the Conjoint Health Research Ethics Board at the University of Calgary. Written informed consent was obtained from all participants. Women aged 40-79 years were recruited from March to May 2005 by the Prospective Health Evaluation Unit in the former Calgary Health Region (now Alberta Health Services) using random digit telephone dialling (RDD). We had a final, target sample size of ninety women ${ }^{(16)}$ based on the number of women required to rule out an intra-class correlation coefficient (ICC) of 0.40 or lower, using a one-sided test at the $5 \%$ level of significance with $80 \%$ power, and assuming approximately $60 \%$ agreement $^{(17)}$. A pool of telephone numbers was randomly generated from available prefixes and cross-referenced with business numbers to exclude known business numbers. Eligible women had a confirmed postal code of residence within the health region and the ability to complete an interview in English. At RDD screening, eligible women were informed that participation entailed completion of three self-administered worksheets and two in-depth telephone interviews. Of the 699 residences identified, we successfully screened 625 (89.4\%) households for an eligible participant. Of the 191 eligible women identified, ninety-seven $(50 \cdot 8 \%)$ refused and ninety-four (49.2\%) agreed to participate. Ultimately, four women completed the first interview only and one woman did not complete the diet interview, leaving ninety women in the sun exposure analysis and eighty-nine women in the dietary analysis.

\section{Measurement of lifetime sun and dietary exposures}

Participants completed telephone interviews for both the OVAL sun survey and the Geraldton survey ${ }^{(7,8)}$ eight weeks apart using a randomized crossover design (Fig. 1). The order of interview completion was determined by generating a random number for each participant study number. Those with odd numbers completed the OVAL survey, then the Geraldton survey ( $n$ 45); while those with even numbers completed the Geraldton survey, then the OVAL survey ( $n$ 45). In preparation for each interview, women were mailed several worksheets to facilitate recall. For the Geraldton survey, women completed a Personal Residence Work Worksheet for each year between 18 and 79 years of age that recorded the following for each age or groups of ages with the same residence/work pattern: calendar year, place of residence, job title or school attended, and number of days per week on and off work/school. For the OVAL survey, women completed the Personal Residence, Work,

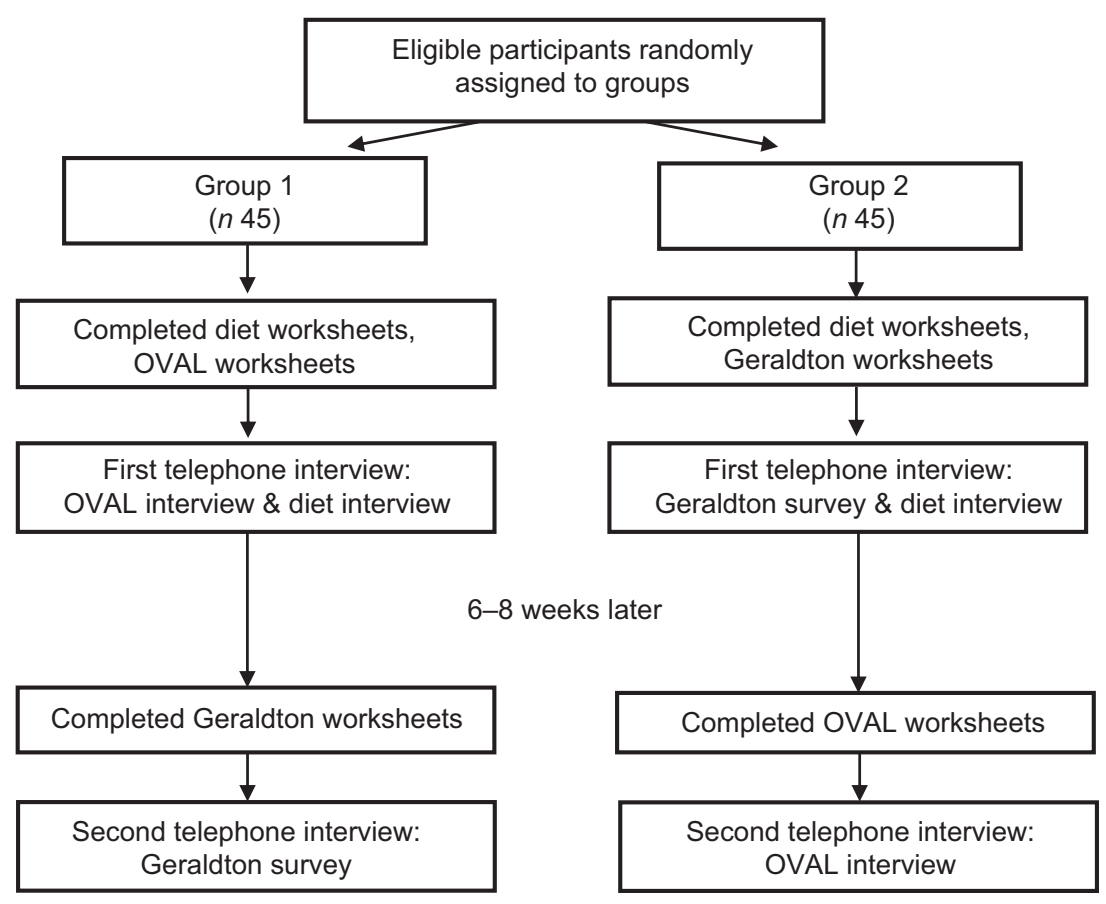

Fig. 1 Flow of participants through the randomized crossover design 
and Holiday Worksheet for specified ages at 10-year age intervals (20, 30 years, etc.) to age 70 years that recorded the following for each age: calendar year, place of residence, job title or school attended, and number of days per week on and off work/school. It also included winter holidays (1 October-31 March for women residing north of $42^{\circ} \mathrm{N}$ and 1 April-30 September for women residing south of $42^{\circ} \mathrm{S}$ ) to a location at a lower latitude than normal residence, because winter sun holidays can impact serum vitamin D concentrations significantly in some populations ${ }^{(18,19)}$. The women also completed a past-year dietary worksheet prior to the first interview only (regardless of which sun survey was completed first) that focused on vitamin D-containing foods/beverages (milk, margarine, tuna, salmon, shrimp, oysters, sardines, eggs) and supplements (multivitamins, vitamin D, cod-liver oil tablets or liquid). This was used at baseline in the interview to help women recall their previous patterns of intake.

To ensure that all worksheets were completed before the interviews, women mailed the completed copy of the worksheets to the study team. Some information (e.g. residential history by age and calendar year) from the worksheets was entered into a computer-assisted telephone interview prior to the interview to reduce interview time.

In the structured telephone interviews, information was recorded that occurred before an assigned reference date (the date of RDD screen) to mirror what would occur in most research studies. The dietary interview, which we developed specifically to estimate vitamin D intake, was adapted from the Canadian modified version of the National Cancer Institute's Diet History Questionnaire ${ }^{(20,21)}$ and estimates, on average, how often and how much vitamin D-containing food was consumed at age 20 years and every tenth year of life thereafter to age 70 years.

\section{Derivation of lifetime vitamin $D$ exposure variables}

To estimate average daily dietary vitamin $\mathrm{D}$ exposure for each study participant, we summed vitamin D intakes (in international units (IU) per day) for each food in our questionnaire, in each age category (20,30, 40 years, etc.). Due to smaller numbers of participants, we collapsed the oldest age categories into a representative period of $60+$ years. For each food item, average daily vitamin D intake was derived as: (consumption frequency per day) $\times$ (portion size in grams) $\times($ vitamin $\mathrm{D}$ content per $100 \mathrm{~g}$ of food) ${ }^{(22)}$. Precise estimates of consumption frequency and portion size were assigned as for the Canadian adaptation of the National Cancer Institute's Diet History Questionnaire ${ }^{(20-24)}$, using the Canadian Nutrient File, or through pilot testing of our questionnaire (for cod-liver oil tablets) ${ }^{(22)}$.

We also estimated the total lifetime and annual mean hours of sun exposure. For the OVAL survey, we used the estimates at every tenth year (20,30, 40 years, etc.), and applied these to 10-year representative periods (20-29, 30-39 years, etc.) for each of the ninety women. As for the diet variables, we collapsed the oldest age categories into a representative period of $60+$ years. For the Geraldton survey, ages with the same sun exposures were determined by each woman (e.g. 20-21, 22-26, 27-34, 35-37 years, etc.), resulting in multiple reported patterns of sun exposure over a fixed 10-year period. To make these estimates analogous to the OVAL survey, we calculated a weighted average of reported exposure with the weight being the number of years for that exposure in the fixed interval. For both instruments, we calculated total lifetime hours by taking a weighted average of weekday and weekend hours spent in the sun, multiplied by number of days in the warmer months per period. We calculated annual averages by dividing total hours by the number of relevant years. In both questionnaires for each pattern of sun exposure, women reported sunscreen use for 1975 and later as never, less than half of the time and greater than half of the time. The OVAL survey is available upon request.

\section{Statistical analysis}

Results are expressed as numbers and proportions, means and their standard errors, or medians with interquartile ranges (IQR) for non-normally distributed data. We calculated the statistics in part with SAS version $9 \cdot 2$ and in part with STATA version 11 statistical software packages. Agreement of the Geraldton and OVAL measures was assessed using two-sided $t$ tests, Spearman rank, Pearson, concordance and intra-class correlation coefficients, and a Bland-Altman analysis ${ }^{(25)}$. The concordance correlation coefficient was calculated using reduced major axis regression analysis, which makes an adjustment to the Pearson correlation for the bias of the regression line away from the line of concordance ${ }^{(26,27)}$. For the Bland-Altman analysis, the difference between the Geraldton and OVAL paired measurements represents the mean bias, which is calculated by adding the differences between paired measurements and dividing the sum by the mean of paired measurements. The limits of agreements between methods are defined as the mean difference \pm 2 SD.

\section{Results}

Estimates of total lifetime adult hours of sun exposure for the OVAL survey strongly correlated with comparable measures from the Geraldton survey (Table 1). The average total lifetime sun exposure was $13913 \mathrm{~h}$ in the Geraldton survey which was slightly higher, but not significantly different from the $13034 \mathrm{~h}$ in the OVAL survey. Higher estimates in the Geraldton survey were most pronounced for the 20-29 years age period (Geraldton OVAL difference: $717 \mathrm{~h}, 95 \%$ CI 284, $1149 \mathrm{~h}$ ). For all other age periods, the confidence interval spanned zero, indicating no significant difference between the instruments. 
Table 1 Average differences and correlations between the Geraldton and OVAL survey lifetime measures of sun exposure among randomly selected women ( $n$ 90) aged $40-79$ years, Calgary, Alberta, Canada, 2004

\begin{tabular}{|c|c|c|c|c|c|c|c|c|c|c|c|c|c|}
\hline \multirow[b]{2}{*}{ Sun exposure } & \multirow[b]{2}{*}{$n$} & \multicolumn{2}{|c|}{ Geraldton survey } & \multicolumn{2}{|c|}{ OVAL survey } & \multicolumn{3}{|c|}{ Geraldton - OVAL difference } & \multicolumn{3}{|c|}{ Correlations } & \multirow[b]{2}{*}{ ICC } & \multirow[b]{2}{*}{$95 \% \mathrm{Cl}$} \\
\hline & & Mean & SE & Mean & SE & Mean & SE & $95 \% \mathrm{Cl}$ & Spearman & Pearson & Concordance* & & \\
\hline \multicolumn{14}{|l|}{ Total $(\mathrm{h})$} \\
\hline $\begin{array}{l}\text { Lifetime } \\
\text { Age (years) }\end{array}$ & 90 & 13913 & 829 & 13034 & 782 & 879 & 537 & $-187,1945$ & 0.73 & 0.78 & 0.77 & 0.77 & $0.69,0.86$ \\
\hline $20-29$ & 90 & 4068 & 228 & 3551 & 235 & 717 & 218 & 284,1149 & 0.52 & 0.56 & 0.53 & 0.52 & $0.37,0.67$ \\
\hline $30-39$ & 90 & 4264 & 222 & 4168 & 237 & 97 & 230 & $-361,554$ & 0.49 & 0.50 & 0.50 & 0.50 & $0.34,0.66$ \\
\hline $40-49$ & 87 & 3263 & 237 & 3129 & 228 & 135 & 188 & $-239,508$ & $0 \cdot 71$ & 0.67 & 0.67 & 0.67 & $0.56,0.79$ \\
\hline $50-59$ & 48 & 2748 & 323 & 2754 & 298 & -6 & 182 & $-372,360$ & $0 \cdot 84$ & 0.83 & 0.83 & 0.83 & $0.74,0.91$ \\
\hline $\begin{array}{c}60+ \\
\text { Mean (h/year) }\end{array}$ & 19 & 4554 & 782 & 4843 & 865 & -290 & 536 & $-1415,836$ & 0.85 & 0.79 & 0.79 & 0.79 & $0.63,0.96$ \\
\hline $\begin{array}{l}\text { Lifetime } \\
\text { Age (vears) }\end{array}$ & 90 & 411 & 18 & 385 & 17 & 26 & 16 & $-5,57$ & 0.58 & 0.60 & 0.60 & 0.60 & $0.47,0.74$ \\
\hline $20-29$ & 90 & 407 & 23 & 335 & 23 & 72 & 22 & 28,115 & 0.52 & 0.56 & 0.53 & 0.52 & $0.37,0.67$ \\
\hline $30-39$ & 90 & 426 & 22 & 417 & 24 & 10 & 23 & $-36,55$ & 0.49 & 0.50 & 0.50 & 0.50 & $0.34,0.66$ \\
\hline $40-49$ & 87 & 394 & 23 & 389 & 23 & 5 & 22 & $-39,49$ & 0.52 & 0.53 & 0.53 & 0.53 & $0.38,0.68$ \\
\hline $50-59$ & 48 & 389 & 31 & 392 & 27 & -5 & 25 & $-54,45$ & 0.58 & 0.65 & 0.64 & 0.65 & $0.48,0.81$ \\
\hline $60+$ & 19 & 496 & 42 & 521 & 57 & -25 & 52 & $-134,83$ & 0.34 & 0.48 & 0.46 & 0.47 & $0.12,0.83$ \\
\hline
\end{tabular}

ICC, intra-class correlation coefficient.

${ }^{*}$ The concordance correlation coefficient is a measure of agreement on a continuous variable obtained by two different methods. $\rho_{\mathrm{c}}=\rho \times C_{\mathrm{b}}$, where $\rho$ is the Pearson coefficient and $C_{\mathrm{b}}$ is a bias correction factor that measures how far the best-fit line deviates from the $45^{\circ}$ line of concordance through the origin.

Although the Spearman rank correlations were the strongest in older age periods, all estimates for the different types of correlations were very similar within each age period and across all ages. Overall, the total lifetime ICC was 0.77 (95\% CI $0 \cdot 69,0 \cdot 86)$, with each 10-year period ICC ranging from $0 \cdot 50$ to $0 \cdot 83$. The concordance correlations for total hours were almost identical to the Pearson correlations, indicating very small bias corrections.

The estimates of annual average sun exposure from the OVAL survey were also significantly correlated with comparable measures from the Geraldton survey (Table 1). Overall, the annual average ICC was 0.60 (95\% CI 0.47, $0 \cdot 74$ ), with that for each 10 -year period ranging from 0.47 to $0 \cdot 65$. Because the annual average sun exposure was calculated as the total hours divided by the relevant number of years, we saw the same pattern of results as for total hours, with the Geraldton survey having slightly higher estimates than the OVAL survey (Geraldton - OVAL difference: $26 \mathrm{~h} /$ year, $95 \% \mathrm{CI}-5,57 \mathrm{~h}$ /year). This is displayed graphically in a Bland-Altman plot (Fig. 2). The plot scatter suggests little systematic bias by magnitude of estimated sun exposure.

We also developed an algorithm to convert sun exposure to vitamin D exposure in IU (the same units as for food and supplements and current public health recommendations) using what has been called the 'Holick formula'(28). In essence, using a number of strong assumptions, we used the minimal erythemal dose (MED; defined as the amount of sun to cause a minimal reddening of the skin) of UVB radiation per hour of sun exposure during the warmer months to estimate a plausible range of the oral vitamin D equivalent in IU for our population. This estimation hinges on the assumption that a full-body exposure to 1 MED of relevant wavelengths of UVB $(\lambda=290-315 \mathrm{~nm})^{(29)}$ results in a rise in serum 25-hydroxyvitamin D (25(OH)D) that

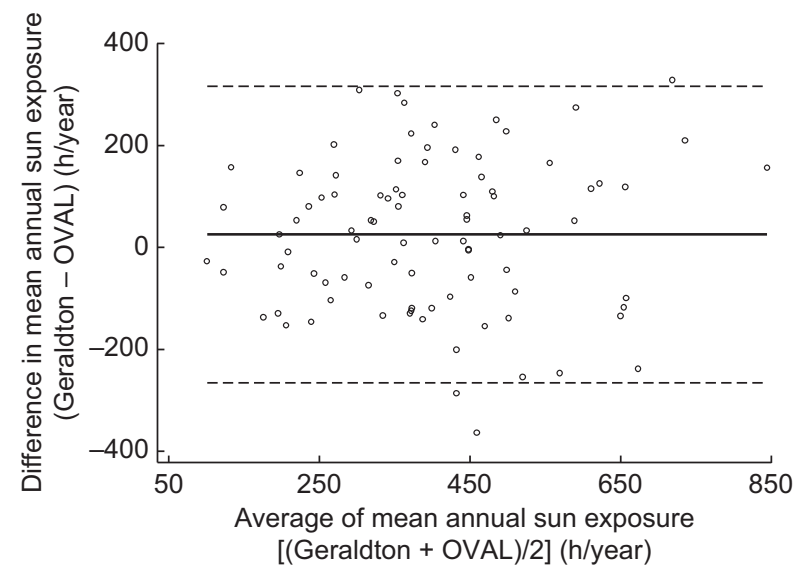

Fig. 2 Bland-Altman plot showing agreement of average annual sun exposure measured from the Geraldton survey and the OVAL survey among randomly selected women ( $n$ 90) aged 40-79 years, Calgary, Alberta, Canada, 2004. represents the mean difference between the two instruments (Geraldton - OVAL: $26 \mathrm{~h} /$ year), - - - - represent the limits of agreement

lies between the measurements obtained from oral doses of ergocalciferol (vitamin $\mathrm{D}_{2}$ ) administered at $10000 \mathrm{IU}$ (250 $\mu \mathrm{g}$; plausible lower bound) and $25000 \mathrm{IU}$ (625 $\mu \mathrm{g}$; plausible upper bound), estimated to be $\approx 20000 \mathrm{IU}$ $(500 \mu \mathrm{g})^{(30)}$. We also assumed that $1 \mathrm{MED}=250 \mathrm{~J} / \mathrm{m}^{2(31)}$ and that the association of ergocalciferol on serum levels of $25(\mathrm{OH}) \mathrm{D}$ is comparable to that of cholecalciferol $\left(\text { vitamin } \mathrm{D}_{3}\right)^{(5)}$. Further assumptions of this model are that a person is lying flat in the equatorial sun at solar noon, at sea level, with the entire body exposed (i.e. 100\% exposure) and is a young to middle-aged adult. We used readily available ambient UV radiation measurements from Edmonton, Alberta, Canada ${ }^{(32)}$, a location that is 
Table 2 Hypothetical estimates of oral vitamin D exposure per hour of sun exposure for a given person in Alberta, Canada for the warmer months of 2004

\begin{tabular}{|c|c|c|c|c|c|c|}
\hline Month of 2004 & $\begin{array}{l}\text { Average daily } \\
\text { irradiation* }\left(\mathrm{J} / \mathrm{m}^{2}\right)\end{array}$ & $\begin{array}{l}\text { Average daily } \\
\text { irradiationt (MED) }\end{array}$ & $\begin{array}{c}\text { Average } \\
\text { sunlight }(\mathrm{h} / \mathrm{d})\end{array}$ & $\begin{array}{l}\text { Average ambient } \\
\mathrm{MED} / \mathrm{h}\end{array}$ & $\begin{array}{c}\text { Plausible oral vitamin D } \\
\text { equivalent }(\mathrm{IU} / \mathrm{h})\end{array}$ & $\begin{array}{l}\text { Lower bound, upper } \\
\text { bound (IU/h)§ }\end{array}$ \\
\hline April & 2153 & $8 \cdot 612$ & $13 \cdot 9$ & 0.6195682 & $210 \cdot 7$ & $105 \cdot 3,263 \cdot 3$ \\
\hline May & 2581 & $10 \cdot 324$ & $15 \cdot 8$ & 0.6534177 & $222 \cdot 2$ & $111 \cdot 1,277 \cdot 7$ \\
\hline June & 3535 & $14 \cdot 140$ & $16 \cdot 9$ & 0.8366863 & $284 \cdot 5$ & $142 \cdot 2,355 \cdot 6$ \\
\hline July & 3153 & $12 \cdot 612$ & $16 \cdot 4$ & 0.7690243 & $261 \cdot 5$ & $130 \cdot 7,326 \cdot 8$ \\
\hline August & 2560 & $10 \cdot 240$ & $14 \cdot 6$ & 0.7013699 & 238.5 & $119 \cdot 2,298 \cdot 1$ \\
\hline \multirow[t]{2}{*}{ September } & 1342 & $5 \cdot 368$ & $12 \cdot 5$ & 0.4294400 & $146 \cdot 0$ & $73 \cdot 0,182 \cdot 5$ \\
\hline & & & & Weighted $\|$ average IU/h: & $227 \cdot 2$ & $113 \cdot 6,284 \cdot 0$ \\
\hline
\end{tabular}

MED, minimal erythemal dose; IU, international unit (to convert to $\mu \mathrm{g}$, divide IU by 40 ).

*For Edmonton, Alberta, Canada ${ }^{(32)}$.

$+1 \mathrm{MED}=250 \mathrm{~J} / \mathrm{m}^{2}$ for Fitzpatrick skin type II, representing a fair Caucasian, used for all calculations ${ }^{(31)}$.

‡From reference 58 .

§Assuming that a full-body exposure to 1 MED results in a rise in serum 25-hydroxyvitamin $D$ that is analogous to an oral dose of ergocalciferol (vitamin $D_{2}$ ) administered at $20000 \mathrm{IU}$ (lower bound: $10000 \mathrm{IU}$, upper bound: $25000 \mathrm{IU}$ ) ${ }^{(30)}$ with a correction for the assumption that, on average, $17 \%$ of all available ambient UV radiation reaches the skin (due to blockage by clouds, buildings, etc.) ${ }^{(33)}$ and that $10 \%$ of the skin is exposed on average (not $\left.100 \%\right)^{(30)}$.

$\|$ Weighted average is weighted by the number of days in each month included in the summary value.

- Example calculation: $2153 \mathrm{~J} / \mathrm{m}^{2}$ irradiation divided by $250 \mathrm{~J} / \mathrm{m}^{2}=8.6120 \mathrm{MED} / \mathrm{d} ; 8 \cdot 16120 \mathrm{MED} / \mathrm{d}$ divided by $13.9 \mathrm{~h} / \mathrm{d}=0.6195682 \mathrm{MED} / \mathrm{h} ; 0.6195682 \mathrm{MED} / \mathrm{h}$ multiplied by $20000 \mathrm{IU}$ multiplied by $0 \cdot 17^{(33)}$ multiplied by $0 \cdot 10^{(30)}=210 \cdot 7 \mathrm{IU} / \mathrm{h}$.

within approximately $3^{\circ}$ latitude and $300 \mathrm{~m}$ altitude of our study population. We further assumed that only $17 \%$ of ambient UV actually reaches a person on account of other factors such as shade from buildings and trees, etc. ${ }^{(33)}$. Using these assumptions we estimated a hypothetical oral vitamin D exposure in IU (with upper and lower bounds) for $1 \mathrm{~h}$ of full-body sun exposure during the warmer months of the year 2004. We further assumed that only $10 \%$ of the body was exposed on average ${ }^{(30)}$ on account of individual factors such as time spent standing, wearing clothing, etc. These hypothetical estimates of plausible oral vitamin $\mathrm{D}$ equivalents per hour of sun exposure, derived as described for our study population, are provided in Table 2.

Using the per hour estimates from Table 2, we also assumed that those aged 60 years or more were $50 \%$ less effective in vitamin D production ${ }^{(34)}$. The plausible oral vitamin D equivalent of the self-reported sun exposure from the OVAL survey for women in our study population ranged from a median of 322 (IQR 207, 404) IU/d $(8 \cdot 05($ IQR $5 \cdot 18-10 \cdot 10) \mu \mathrm{g} / \mathrm{d})$ for the $60+$ years group to 465 (IQR 332-584) IU/d (11.63 (IQR 8.30-14.60) $\mu \mathrm{g} / \mathrm{d})$ for the 50-59 years group (Table 3 ). The overall median of dietary and supplement intake of vitamin $\mathrm{D}$ in this population was 318 (IQR 176-476) IU/d (7.95 (IQR $4 \cdot 40-11 \cdot 90) \mu \mathrm{g} / \mathrm{d}$ ). Vitamin $\mathrm{D}$ intake increased with increasing age periods, from a median of 212 (IQR 102-425) IU/d $(5 \cdot 30(I Q R ~ 2 \cdot 55-10 \cdot 63) \mu \mathrm{g} / \mathrm{d})$ in the 20-29 years group to 685 (IQR 444-890) IU/d (17.13 (IQR $11 \cdot 10-22 \cdot 25) \mu \mathrm{g} / \mathrm{d}$ ) in the $60+$ years group. We combined these values with the estimates from sun exposure to estimate total combined vitamin D exposure, which ranged from a median of 660 (IQR 421-883) IU/d (16.50 (IQR $10 \cdot 53-22 \cdot 01) \mu \mathrm{g} / \mathrm{d}$ ) for ages $20-29$ years to 1004 (IQR 864-1181) IU/d (25.03 (IQR 21.60-29.53) $\mu \mathrm{g} / \mathrm{d}$ ) in the $60+$ years group. Relating these results to the 'adequate intakes' of vitamin D that were recognized when the study was conducted ${ }^{(35)}$, between $51.7 \%$ and $83.3 \%$ of women (depending on age group) met adequate vitamin $\mathrm{D}$ intakes through diet and supplements (Table 4). If we add sun exposure as IU of vitamin D, then $>90 \%$ of women, regardless of age group, would have met these historical adequate levels during the warmer months of the year. Analogous estimates were made adjusting for sunscreen use (Tables 3 and 4).

\section{Discussion}

In a randomly sampled population of Canadian women, the results of our study show that the OVAL survey reliably reproduces measurements from the gold standard Geraldton survey for both total hours and average hours per year of sun exposure for months of the year with sufficient UV radiation for vitamin D production. Thus, capturing every tenth year for the purpose of estimating lifetime sun exposure is both reliable and efficient when estimating adult sun exposure. We also collected estimates of vitamin D intake for every tenth year in the OVAL survey, and found that average dietary intake increased with age in our study population. Our success capturing this retrospective vitamin D intake demonstrates feasibility, but we were not able to assess the reliability of the dietary intake estimates as we know of no other instrument that assesses dietary and supplement intake over adult life.

The good to excellent correlations between the OVAL survey and the Geraldton survey suggest that the two instruments are capturing similar information on sun exposure. However, the true validity (against an objective gold standard) of the Geraldton survey or any other sun exposure instrument that captures many years is difficult to assess given the time, resources and expense required to measure sun exposure objectively over an entire adult 
Table 3 Estimated vitamin D exposure (IU/d) from self-reported diet, supplement use and sun exposure in the OVAL survey among randomly selected women ( $n$ 90) aged 40-79 years, Calgary, Alberta, Canada, 2004

\begin{tabular}{|c|c|c|c|c|c|c|c|c|c|c|c|c|c|}
\hline & \multirow[b]{2}{*}{$n$} & \multicolumn{2}{|c|}{$\begin{array}{l}\text { Average self-reported sun } \\
\text { exposure }(\mathrm{h} / \mathrm{d})\end{array}$} & \multicolumn{2}{|c|}{$\begin{array}{l}\text { Average oral vitamin } D \\
\text { equivalent estimated from } \\
\text { sun exposure* }(\mathrm{IU} / \mathrm{d})\end{array}$} & \multicolumn{2}{|c|}{$\begin{array}{l}\text { Average oral vitamin } D \\
\text { equivalent estimated from } \\
\text { sun exposure }{ }^{\star} \text {, adjusted } \\
\text { for sunscreen uset (IU/d) }\end{array}$} & \multicolumn{2}{|c|}{$\begin{array}{l}\text { Self-reported total vitamin } \\
\text { D from food and } \\
\text { supplements (IU/d) }\end{array}$} & \multicolumn{2}{|c|}{$\begin{array}{l}\text { Total estimated vitamin D } \\
\text { from food, supplements } \\
\text { and sun (IU/d) }\end{array}$} & \multicolumn{2}{|c|}{$\begin{array}{l}\text { Total estimated vitamin D } \\
\text { from food, supplements } \\
\text { and sun, adjusted for } \\
\text { sunscreen use (IU/d) }\end{array}$} \\
\hline & & Median & IQR & Median & IQR & Median & IQR & Median & IQR & Median & IQR & Median & IQR \\
\hline $\begin{array}{l}\text { Lifetime } \\
\text { Age (years) }\end{array}$ & 89 & $2 \cdot 04$ & $1 \cdot 51-2 \cdot 62$ & 463 & $343-594$ & 378 & $280-485$ & 318 & $176-476$ & 799 & 640-998 & 652 & $523-815$ \\
\hline $20-29$ & 89 & 1.50 & $1 \cdot 00-2 \cdot 43$ & 341 & $227-551$ & 287 & $191-465$ & 212 & $102-425$ & 660 & $421-883$ & 557 & $355-745$ \\
\hline $30-39$ & 89 & $2 \cdot 00$ & $1 \cdot 29-3 \cdot 00$ & 454 & $292-681$ & 324 & $208-486$ & 291 & $111-476$ & 871 & $551-1079$ & 622 & $393-770$ \\
\hline $40-49$ & 86 & 1.96 & $1 \cdot 36-2 \cdot 71$ & 446 & $310-616$ & 293 & 204-405 & 310 & $133-532$ & 764 & $567-1003$ & 502 & $376-657$ \\
\hline $50-59$ & 47 & $2 \cdot 05$ & $1 \cdot 43-2 \cdot 57$ & 465 & $332-584$ & 376 & $269-472$ & 484 & $247-808$ & 976 & $743-1345$ & 789 & $610-1067$ \\
\hline $60+$ & 18 & $2 \cdot 83$ & $1 \cdot 82-3 \cdot 57$ & $322 \ddagger$ & $207-404$ & 302 & $195-379$ & 685 & $444-890$ & 1004 & $864-1181$ & 942 & $811-1109$ \\
\hline
\end{tabular}

IU, international unit (to convert to $\mu$ g, divide IU by 40 ); IQR, interquartile range.

*Derived using approach in Table 2.

(he the $(75 \%$ reduction).

tReduced by $50 \%$ to account for reduced vitamin $\mathrm{D}$ production in the skin at older ages ${ }^{(34)}$.

Table 4 Percentage meeting recommended intakes (both historical and current) with reported sun and dietary exposures for times of the year with adequate irradiation to stimulate vitamin $D$ production among randomly selected women $(n 90)$ aged 40-79 years, Calgary, Alberta, Canada, 2004

\begin{tabular}{|c|c|c|c|c|c|c|c|c|c|}
\hline $\begin{array}{l}\text { Age group } \\
\text { (years) }\end{array}$ & $n$ & $\begin{array}{c}\text { Historical } \\
\text { adequate intake* } \\
\text { (IU/d) }\end{array}$ & $\begin{array}{l}\% \text { of women who } \\
\text { met/exceeded } \\
\text { adequate intake } \\
\text { through intaket } \\
\text { alone }\end{array}$ & $\begin{array}{l}\% \text { of women who } \\
\text { met/exceeded } \\
\text { adequate intake } \\
\text { through intaket } \\
\text { and sun } \\
\text { exposure }\end{array}$ & $\begin{array}{l}\% \text { of women who } \\
\text { met/exceeded } \\
\text { adequate intake } \\
\text { through intaket and } \\
\text { sun exposure, } \\
\text { adjusted for } \\
\text { sunscreen use }\end{array}$ & $\begin{array}{l}\text { Current } \\
\text { recommended } \\
\text { intake }(\text { (IU/d) }\end{array}$ & $\begin{array}{l}\% \text { of women who } \\
\text { would meet/exceed } \\
\text { recommendations } \\
\text { through intaket } \\
\text { alone }\end{array}$ & $\begin{array}{l}\text { \% of women who would } \\
\text { meet/exceed current } \\
\text { recommendations } \\
\text { through intaket and } \\
\text { sun exposure }\end{array}$ & $\begin{array}{l}\text { \% of women who would } \\
\text { meet/exceed current } \\
\text { recommendations } \\
\text { through intaket and sun } \\
\text { exposure, adjusted for } \\
\text { sunscreen use }\end{array}$ \\
\hline $20-29$ & 89 & 200 & $51 \cdot 7$ & $95 \cdot 5$ & 94.4 & 600 & $14 \cdot 6$ & $59 \cdot 6$ & 38.2 \\
\hline $30-39$ & 89 & 200 & $62 \cdot 9$ & $98 \cdot 9$ & $95 \cdot 5$ & 600 & $12 \cdot 4$ & $71 \cdot 9$ & $51 \cdot 7$ \\
\hline $40-49$ & 86 & 200 & 60.5 & 98.8 & $95 \cdot 3$ & 600 & $12 \cdot 8$ & $73 \cdot 3$ & 32.6 \\
\hline 50-59 & 47 & 400 & $59 \cdot 6$ & 93.6 & $93 \cdot 6$ & 600 & $38 \cdot 3$ & $89 \cdot 4$ & $76 \cdot 6$ \\
\hline $60-69$ & 12 & 400 & $83 \cdot 3$ & $100 \cdot 0$ & $100 \cdot 0$ & 600 & $58 \cdot 3$ & $90 \cdot 9$ & $90 \cdot 9$ \\
\hline $70+$ & 6 & 600 & $66 \cdot 7$ & $100 \cdot 0$ & $100 \cdot 0$ & 800 & $33 \cdot 3$ & $100 \cdot 0$ & $100 \cdot 0$ \\
\hline
\end{tabular}

IU, international unit (to convert to $\mu \mathrm{g}$, divide IU by 40 ).

*From reference 35

+Intake includes intake through both diet and supplements.

fBased on estimates in Table 3.

\$From references 45 and 46 . 
life through means such as personal UV dosimetry. Selfreported short periods (1 year or less) of sun exposure have been validated using independent observers ${ }^{(36)}$ or personal UV dosimetry ${ }^{(6,37)}$; correlations have ranged from quite low to high depending on the type of sun exposure measured and the length of time assessed. Another validation measure, solar skin damage (actinic damage), was positively associated with greater cumulative hours of sun exposure derived from questionnaires in one study $(P \text { for trend }=0.001)^{(38)}$ but had a low correlation $(r=0 \cdot 05)$ in another study ${ }^{(39)}$. Greater amounts of reported recent sun exposure also have been significantly correlated with serum $25(\mathrm{OH}) \mathrm{D}$ levels (e.g. reference 9), as have short courses of narrowband UVB exposure (e.g. reference 40). Given that serum 25(OH)D levels can vary with vitamin D intake, season, sun exposure and a number of other factors ${ }^{(4,41)}$, it is probably not reasonable to use a single serum measure of vitamin $\mathrm{D}$ as a surrogate for adult lifetime sun exposure. Thus, a true validation of reported lifetime sun exposures that might influence chronic disease risk $^{(42,43)}$ continues to be a challenge.

Based on the dietary and supplement intakes only, our results suggests that between $51.7 \%$ and $83.3 \%$ of women (depending on age group) met adequate vitamin $\mathrm{D}$ intakes that were in place in Canada when the study was conducted ${ }^{(35)}$. Our estimated intake values are consistent with those estimated from $24 \mathrm{~h}$ recalls in the third National Health and Nutrition Examination Survey and the Continuing Survey of Food Intakes in the USA ${ }^{(44)}$. Similar to our results on an individual level, these large surveys also found that total dietary and supplement intake of vitamin D increased with age on a cross-sectional level ${ }^{(44)}$. At face value, these results seem reasonable because the recommended daily intakes of $\mathrm{Ca}$ and vitamin $\mathrm{D}$ for older individuals increase for bone health ${ }^{(45,46)}$. These results suggest that vitamin $\mathrm{D}$ intakes are not consistent over adult life and that measurement of intake in a 1-year period (such as that in FFQ in cohort studies) may not adequately capture vitamin D intakes that may be relevant to chronic disease diagnoses many years later.

In 2010, the US Institute of Medicine released new dietary recommended intakes for vitamin $\mathrm{D}^{(45)}$ in a report commissioned by the US and Canadian governments ${ }^{(47)}$. Also in 2011, a US-directed international task force published similar recommendations for adults at risk for vitamin $\mathrm{D}$ deficiency ${ }^{(46)}$. Only $12.4 \%$ and $58.3 \%$ of women in our study (depending on age period) would have met these new recommendations based on dietary and supplement intake. Neither the Institute of Medicine nor the task force included sun exposure in its recommendations ${ }^{(45,46)}$. However, if we accept all the strong assumptions made in estimating sun exposure as IU of vitamin $\mathrm{D}$, then our analysis suggests that, when sun exposure is considered with vitamin D intake, a high percentage of women in our study would have met both the historical and current recommendations ( $>90 \%$ for historical and $59 \cdot 6 \%$ to $100 \%$ for current) for the warmer months of the year. Regardless of age, about $28 \%$ of women did not meet the new recommendations with intake and sun exposure which is consistent with an estimated $20-23 \%$ of Canadians having serum values $<50 \mathrm{nmol} / 1$ ( $50 \mathrm{nmol} / \mathrm{l}$ is roughly consistent with the RDA intake of 600-800 IU (15-20 $\mu \mathrm{g})$ ) during the summer months ${ }^{(48)}$.

Given the strong assumptions in this analysis, any of our individual estimates of vitamin D exposure via sun exposure must be interpreted cautiously. Cholecalciferol production in the skin depends upon many factors including: exposure to wavelengths of UVB radiation between $\lambda=290 \mathrm{~nm}$ and $\lambda=315 \mathrm{~nm}$; the amount of UVB exposure; season of the year; latitude, altitude and time of day; fraction of skin exposed to UVB; solar zenith angle, ozone column, cloud cover, ground and cloud albedo; duration of UVB exposure; amount of pre cholecalciferol available in the skin and skin type (amount of pigmentation); sunscreen application; age; BMI; disease status and medications consumed. It is not surprising, then, that other approaches to estimating UVB-derived vitamin D exposure have been described in the literature (e.g. references 49 and 50) that differ from our own. We did not collect information on BMI, disease status or medications for this reliability study. Nor did we describe our analyses accounting for skin pigmentation ${ }^{(51)}$ because the women in the study self-identified as white. However, we did account for reported sunscreen use in our estimates of oral vitamin D equivalent (Tables 3 and 4). Whether or not the adjustment for sunscreen use is valid is unknown as some evidence from the literature indicates sunscreen use does not reduce UVB exposures when self-applied ${ }^{(52-56)}$, although sunscreen applied under controlled research conditions at a sufficient thickness and sun protection factor can prevent significant increases in serum $25(\mathrm{OH}) \mathrm{D}$ from occurring ${ }^{(57)}$. Nevertheless, our estimates do support the idea that a substantial proportion of vitamin $\mathrm{D}$ comes from sun exposure in the warmer months relative to that from diet and supplements, even with adjustment for sunscreen use.

In this inter-method reliability study, we found that our OVAL survey reliably estimated adult sun exposure relative to the gold standard Geraldton survey for months of the year that are relevant to vitamin D production for our study population. Thus, capturing relevant adult sun exposure every tenth year to estimate lifetime sun exposure is reasonable, reliable and efficient. We also found that diet and supplement intakes of vitamin D were relatively modest in our study population. More speculatively, we found that sun exposure may exceed the contribution of dietary intake to total vitamin $\mathrm{D}$ in the everyday, real-life experience of these women in the warmer months of the year. Any means to further improve our ability to capture sun exposure in an efficient and cost-effective manner, either via objective means or self-report, will assist in our efforts to elucidate the role of vitamin $\mathrm{D}$ in chronic disease risk. 


\section{Acknowledgements}

Sources of funding: This research was supported by a grant from the Canadian Institutes of Health Research (MOP-68977). L.S.C. was supported through a Canada Research Chair and the Alberta Heritage Foundation for Medical Research until 2007. Conflicts of interest: The authors declare no conflict of interest in relation to this manuscript. Authors' contributions: L.S.C. and H.K.N. designed the research; L.S.C. conducted the research; B.L.M., Y.D. and H.K.N. analysed the data; L.S.C., B.L.M., Y.D. and H.K.N. wrote the paper; L.S.C. had primary responsibility for final content. All authors read and approved the final manuscript. Acknowledgements: The authors thank Robert C. Lee for his helpful review of this manuscript.

\section{References}

1. Muscogiuri G, Sorice GP, Ajjan R et al. (2012) Can vitamin D deficiency cause diabetes and cardiovascular diseases? Present evidence and future perspectives. Nutr Metab Cardiovasc Dis 22, 81-87.

2. Wang L, Song Y, Manson JE et al. (2012) Circulating 25-hydroxy-vitamin D and risk of cardiovascular disease: a meta-analysis of prospective studies. Circ Cardiovasc Qual Outcomes 5, 819-829.

3. Cutolo M, Pizzorni C \& Sulli A (2011) Vitamin D endocrine system involvement in autoimmune rheumatic diseases. Autoimmun Rev 11, 84-87.

4. International Agency for Research on Cancer (2008) Vitamin D and Cancer. IARC Working Group Reports, vol. 5. Lyon: IARC.

5. Millen AE \& Bodnar LM (2008) Vitamin D assessment in population-based studies: a review of the issues. Am J Clin Nutr 87, issue 4, 1102S-1105S.

6. McCarty CA (2008) Sunlight exposure assessment: can we accurately assess vitamin D exposure from sunlight questionnaires? Am J Clin Nutr 87, issue 4, 1097S-1101S.

7. English DR, Armstrong BK \& Kricker A (1998) Reproducibility of reported measurements of sun exposure in a case-control study. Cancer Epidemiol Biomarkers Prev 7, 857-863.

8. Kricker A, Armstrong BK, Jones ME et al. (1993) Health, Solar UV Radiation and Environmental Change. Lyon: IARC.

9. van der Mei IA, Blizzard L, Ponsonby AL et al. (2006) Validity and reliability of adult recall of past sun exposure in a case-control study of multiple sclerosis. Cancer Epidemiol Biomarkers Prev 15, 1538-1544.

10. Kricker A, Vajdic CM \& Armstrong BK (2005) Reliability and validity of a telephone questionnaire for estimating lifetime personal sun exposure in epidemiologic studies. Cancer Epidemiol Biomarkers Prev 14, 2427-2432.

11. Yu CL, Li Y, Freedman DM et al. (2009) Assessment of lifetime cumulative sun exposure using a self-administered questionnaire: reliability of two approaches. Cancer Epidemiol Biomarkers Prev 18, 464-471.

12. Thomas MK, Lloyd-Jones DM, Thadhani RI et al. (1998) Hypovitaminosis D in medical inpatients. $N$ Engl $J$ Med 338, 777-783.

13. Blalock SJ, Norton LL, Patel RA et al. (2003) Development and assessment of a short instrument for assessing dietary intakes of calcium and vitamin D. J Am Pharm Assoc 43, 685-693.
14. Pritchard JM, Seechurn T \& Atkinson SA (2010) A food frequency questionnaire for the assessment of calcium, vitamin D and vitamin K: a pilot validation study. Nutrients 2, 805-819.

15. Nakamura K, Nashimoto M, Hori Y et al. (2000) Serum 25-hydroxyvitamin $\mathrm{D}$ concentrations and related dietary factors in peri- and postmenopausal Japanese women. $\mathrm{Am}$ J Clin Nutr 71, 1161-1165.

16. Kraemer HC \& Thiemann S (1987) How Many Subjects? Statistical Power Analysis in Research. Newbury Park, CA: Sage Publications Inc.

17. Landis JR \& Koch GG (1977) The measurement of observer agreement for categorical data. Biometrics 33, 159-174.

18. Brustad M, Alsaker E, Engelsen O et al. (2004) Vitamin D status of middle-aged women at 65-71 degrees $\mathrm{N}$ in relation to dietary intake and exposure to ultraviolet radiation. Public Health Nutr 7, 327-335.

19. Dawson-Hughes B, Harris SS \& Dallal GE (1997) Plasma calcidiol, season, and serum parathyroid hormone concentrations in healthy elderly men and women. Am J Clin Nutr 65, 67-71.

20. National Institutes of Health, Applied Research Program, National Cancer Institute (2002) Diet History Questionnaire, Version 1.O. Bethesda, MD: NCI; available at http://riskfactor. cancer.gov/DHQ

21. Csizmadi I, Kahle L, Ullman R et al. (2007) Adaptation and evaluation of the National Cancer Institute's diet history questionnaire and nutrient database for Canadian populations. Public Health Nutr 10, 88-96.

22. Nutrition Research Division, Health Canada (accessed 2005) Canadian Nutrient File, Version 2001b. Ottawa: Health Canada; available at http://www.hc-sc.gc.ca/fn-an/nutrition/ fiche-nutri-data/cnf_aboutus-aproposdenous_fcen-eng.php

23. National Cancer Institute, Applied Research Program (2005) Diet*Calc Analysis Program, Version 1.4.3. Bethesda, MD: NCI; available at http://riskfactor.cancer.gov/DHQ/dietcalc/

24. National Cancer Institute, Applied Research Program (2004) DHQ Nutrient Database, dhq1_081704.csv. Bethesda, MD: NCI; described at http://riskfactor.cancer.gov/DHQ/database/ dbchanges.html

25. Bland JM \& Altman DG (1986) Statistical methods for assessing agreement between two methods of clinical measurement. Lancet 1, 307-310.

26. Smith RJ (2009) Use and misuse of the reduced major axis for line-fitting. Am J Phys Anthropol 140, 476-486.

27. Lin LI (1989) A concordance correlation coefficient to evaluate reproducibility. Biometrics 45, 255-268.

28. Holick MF (1995) Environmental factors that influence the cutaneous production of vitamin D. Am J Clin Nutr 61, 3 Suppl., 638S-645S.

29. Commission Internationale de l'Eclairage (2006) CIE 174:2006 Action Spectrum for the Production of Previtamin $D_{3}$ in Human Skin. Vienna: CIE.

30. Holick MF (2004) Vitamin D: importance in the prevention of cancers, type 1 diabetes, heart disease, and osteoporosis. Am J Clin Nutr 79, 362-371.

31. Fitzpatrick TB (1988) The validity and practicality of sunreactive skin types I through VI. Arch Dermatol 124, 869-871.

32. Meteorological Service of Canada (Atmospheric Environment Service) (not dated) Global archive of ground-based ozone and UV data products. World Ozone and Ultraviolet Radiation Data Centre (WOUDC) operated by Environment Canada, Toronto, ON. http://www.woudc.org (accessed June 2010).

33. Diffey B (2008) A behavioral model for estimating population exposure to solar ultraviolet radiation. Photochem Photobiol 84, 371-375.

34. MacLaughlin J \& Holick MF (1985) Aging decreases the capacity of human skin to produce vitamin $\mathrm{D}_{3}$. J Clin Invest 76, 1536-1538. 
35. National Research Council (1997) Dietary Reference Intakes for Calcium, Phosphorus, Magnesium, Vitamin D, and Fluoride. Washington, DC: The National Academies Press.

36. O'Riordan DL, Lunde KB, Steffen AD et al. (2006) Validity of beachgoers' self-report of their sun habits. Arch Dermatol 142, 1304-1311.

37. Humayun Q, Iqbal R, Azam I et al. (2012) Development and validaton of sunlight exposure measurement questionnaire (SEM-Q) in an adult population residing in Pakistan. BMC Public Health 12, 421.

38. Karagas MR, Zens MS, Nelson HH et al. (2007) Measures of cumulative exposure from a standardized sun exposure history questionnaire: a comparison with histologic assessment of solar skin damage. Am J Epidemiol 165, 719-726.

39. John EM, Schwartz GG, Dreon DM et al. (1999) Vitamin D and breast cancer risk: the NHANES I Epidemiologic follow-up study, 1971-1975 to 1992. National Health and Nutrition Examination Survey. Cancer Epidemiol Biomarkers Prev 8, 399-406.

40. Ala-Houhala MJ, Vahavihu K, Hasan T et al. (2012) Comparison of narrowband ultraviolet $\mathrm{B}$ exposure and oral vitamin D substitution on serum 25-hydroxyvitamin D concentration. Br J Dermatol 167, 160-164.

41. Hypponen E \& Power C (2007) Hypovitaminosis D in British adults at age $45 \mathrm{y}$ : nationwide cohort study of dietary and lifestyle predictors. Am J Clin Nutr 85, 860-868.

42. John EM, Koo J \& Schwartz GG (2007) Sun exposure and prostate cancer risk: evidence for a protective effect of early-life exposure. Cancer Epidemiol Biomarkers Prev 16, 1283-1286.

43. Yang L, Veierod MB, Lof M et al. (2011) Prospective study of UV exposure and cancer incidence among Swedish women. Cancer Epidemiol Biomarkers Prev 20, 1358-1367.

44. Moore C, Murphy MM, Keast DR et al. (2004) Vitamin D intake in the United States. J Am Diet Assoc 104, 980-983.

45. Institute of Medicine of the National Academies, Committee to Review Dietary Reference Intakes for Vitamin D and Calcium (2010) Dietary Reference Intakes for Calcium and Vitamin D [AC Ross, CL Taylor, AL Yaktine et al., editors]. Washington, DC: The National Academies Press.

46. Holick MF, Binkley NC, Bischoff-Ferrari HA et al. (2011) Evaluation, treatment, and prevention of vitamin D deficiency: an Endocrine Society clinical practice guideline. J Clin Endocrinol Metab 96, 1911-1930.
47. Health Canada (2012) Vitamin D and Calcium: Updated Dietary Reference Intakes. Ottawa: Health Canada; available at http://www.hc-sc.gc.ca/fn-an/nutrition/vitamin/ vita-d-eng.php\#t4

48. Whiting SJ, Langlois KA, Vatanparast $\mathrm{H}$ et al. (2011) The vitamin D status of Canadians relative to the 2011 dietary reference intakes: an examination in children and adults with and without supplement use. Am J Clin Nutr 94, 128-135.

49. Giovannucci E, Liu Y, Rimm EB et al. (2006) Prospective study of predictors of vitamin D status and cancer incidence and mortality in men. J Natl Cancer Inst 98, 451-459.

50. Fioletov VE, McArthur LJ, Mathews TW et al. (2010) Estimated ultraviolet exposure levels for a sufficient vitamin D status in North America. J Photochem Photobiol B 100, 57-66.

51. Clemens TL, Adams JS, Henderson SL et al. (1982) Increased skin pigment reduces the capacity of skin to synthesise vitamin $\mathrm{D}_{3}$. Lancet 1, 74-76.

52. Farrerons J, Barnadas M, Rodriguez J et al. (1998) Clinically prescribed sunscreen (sun protection factor 15) does not decrease serum vitamin $\mathrm{D}$ concentration sufficiently either to induce changes in parathyroid function or in metabolic markers. BrJ Dermatol 139, 422-427.

53. Marks R, Foley PA, Jolley D et al. (1995) The effect of regular sunscreen use on vitamin D levels in an Australian population. Results of a randomized controlled trial. Arch Dermatol 131, 415-421.

54. Matsuoka LY, Wortsman J \& Hollis BW (1990) Use of topical sunscreen for the evaluation of regional synthesis of vitamin $\mathrm{D}_{3}$. J Am Acad Dermatol 22, 772-775.

55. Thieden E, Philipsen PA, Sandby-Moller J et al. (2005) Sunscreen use related to UV exposure, age, sex, and occupation based on personal dosimeter readings and sunexposure behavior diaries. Arch Dermatol 141, 967-973.

56. Matsuoka LY, Ide L, Wortsman J et al. (1987) Sunscreens suppress cutaneous vitamin $\mathrm{D}_{3}$ synthesis. J Clin Endocrinol Metab 64, 1165-1168.

57. Faurschou A, Beyer DM, Schmedes A et al. (2012) The relation between sunscreen layer thickness and vitamin D production after ultraviolet B exposure: a randomized clinical trial. Br J Dermatol 167, 391-395.

58. timeanddate.com (1995-2012) Sunrise and sunset in Edmonton. Copyright (C) Time and Date AS 1995-2012. All rights reserved. http://www.timeanddate.com/world clock $/$ astronomy.html? $n=80 \&$ month $=5 \& y e a r=2004 \& o b j=$ sun\&afl $=-11 \&$ day $=1$ (accessed June 2010). 